\title{
Prediction of difficult laparoscopic cholecystectomy while working up the patient for surgery
}

\author{
Kumar $\mathbf{N}^{1}$, Bhutia $\mathrm{P}^{2}$, Singh V.K ${ }^{3}$, Kharga B ${ }^{4}$, Sharma B.K $\mathbf{K}^{5}$, Jain $\mathbf{N}^{6}$ \\ ${ }^{1}$ Dr. Kumar Nishant, Associate Professor, ${ }^{2}$ Dr. Phuchungla Bhutia, Assistant Professor, ${ }^{3}$ Dr. Varun Kumar Singh, Associate \\ Professor, ${ }^{4}$ Dr. Bikram Kharga, Professor, All these authors are affiliated with Department of Surgery, Sikkim Manipal \\ Institute of Medical Sciences, Gangtok, ${ }^{5}$ Dr. Barun Kumar Sharma, Associate Professor, Department of Radiodiagnosis, \\ North East Indira Gandhi Regional Institute of Health and Medical Sciences, Shillong, ${ }^{6}$ Dr. Nitin Jain, Senior Resident, \\ Department of Paediatric Surgery, Maulana Azad Medical College, Delhi, India.
}

Address for Correspondence: Dr. Phuchungla Bhutia, E-Mail Id: david999ran@gmail.com

\begin{abstract}
Introduction:Laparoscopic cholecystectomy [LC] has established itself as standard of care for gallstone disease. With the wide availability of expertise, complication rate and conversion rate both are coming down. Coupled with increase in patient awareness and easy accessibility of information, it is becoming increasingly difficult for surgical team to explain complication arising following surgery. A preoperative prediction can help ease doctor-patient relationship. Objective: To find out the predictors of difficult laparoscopic cholecystectomy while investigating the patient for surgery. Patient and methods: We selected 125 patients based on convenient sampling who underwent LC. A Likert type questionnaire was used to assess the difficulty. Weighted difficulty score [WDS] was calculated as the sum of product of parameter response and difficulty response score $\left[\mathrm{WDS}=\sum(\mathrm{PR} \times \mathrm{DRS})\right]$. Mean WDS was then compared against preoperative investigation findings. Results: Mean WDS was found to increase with raised leukocyte count as well as with altered liver function tests. Thickened gallbladder wall in ultrasonography had a positive correlation with difficulty in surgery but no association was found with the pericholecystic fluid. A larger size of stone, stone impacted at neck and a larger size of the impacted stone were all had a significant positive association with difficult LC but number of stones in GB had no impact on difficulty during surgery in our study. Altered liver echotexture and a contracted GB were the other factors which can predict a possible difficulty during LC. Conclusion: A careful watch on investigation which include leukocyte count, liver function tests and preoperative ultrasonography can help predict the difficulty, a possibility of conversion as well as complications. A discussion of these events with the patients and their relatives can create an atmosphere of mutual trust and better prepare to overcome of untoward events.
\end{abstract}

Key words- Cholecystectomy, Difficult, Laparoscopic, Weighted Difficulty Score

\section{Introduction}

Laparoscopic cholecystectomy [LC] has established itself as the standard of care for symptomatic gallstone disease [1]. With the wide availability of expertise, the complication rate and conversion rate both are coming down. Coupled with the increase in the patient awareness and easy accessibility of information, it is becoming increasingly difficult for the surgical team to explain patients and their relatives to accept the complications that can arise following surgery. In the era of litigation, these untoward events may have significant consequences for everyone involved in the patient care. Because of high volume of cases, these consequences are increased several

Manuscript Received: $18^{\text {th }}$ October 2017

Reviewed: $28^{\text {th }}$ October 2017

Author Corrected: $4^{\text {th }}$ November 2017

Accepted for Publication: $10^{\text {th }}$ November 2017 folds. On one hand, high volume of cases can enhance the surgical skills of the beginners, on the other hand can induce a tendency to take the surgery casually thus creating surprises in difficult cases. Anatomical variations in hepatobiliary system are common and can be present in about $30 \%$ of the population [2]. Any injury to them can cause significant morbidity bringing bad name to surgical team. And even if morbidityis avoided, a lot of already planned time is lost.

The study was planned to know whether or not a difficult laparoscopic surgery could be predicted in order to help the patients develop a better understanding of "the things can go wrong even in best of hands and safest of procedures" and thus ease the doctor-patient relationship. 
Original Research Article

\section{Objective}

To identify risk factors during investigating and preparing the patient for surgery, responsible for technically difficult laparoscopic cholecystectomy.

\section{Methods}

Study design- The study was conceived as a prospective analytical study. Patients were selected using convenient sampling method.

Setting- The study was conducted in Central Referral Hospital associated to Sikkim Manipal Institute of Medical Sciences, Gangtok from August 2012 to July 2013.

Inclusion and exclusion criteria- A total of 125 patients were included who fulfilled the inclusion criteria. The inclusion and exclusion criteria have been listed in table/figure1.

Table 1: Inclusion and exclusion criteria.

\begin{tabular}{|l|l|}
\hline Inclusion Criteria & Exclusion Criteria \\
\hline 1. Symptomatic gallstone disease & 1. Equipment or other technical failure, \\
2. Asymptomatic gallstone disease with following & 2. Complicated cholelithiasis [pancreatitis, choledocholithiasis] \\
a. Size of calculus $<3 \mathrm{~mm}$ or $>3 \mathrm{~cm}$ & 3. Co-morbidities other than hypertension or diabetes mellitus \\
b. Associated polyp & 4. Surgeon's experience of $<30$ cases/ 1 year \\
c. Life expectancy $>20$ years & 5. Reduced port surgeries \\
d. Associated diabetes mellitus & \\
\hline
\end{tabular}

Outcome variable- Difficult LC was the outcome variable. To assess the difficulty, we sent a Likert type questionnaire to practising laparoscopic surgeons across the country using Google ${ }^{\odot}$ Forms $^{\odot}$ [table/figure3] and then calculated a weighted difficulty score $\left[W D S=\sum\right.$ (PR x DRS)]. PR was the parameter response recorded as one or zero for its presence or absence, respectively and DRS was the difficulty response score measured on a scale from 1 to 5 . Mean WDS was then compared against preoperative investigations.

Procedure standardization- The operative protocol was standardized. We have total 8 surgeons in the department who perform laparoscopic surgeries but cases of 5 surgeons were counted as only they had sufficient experience as laid by the exclusion criteria. Only those cases were included which were performed using 4 standard ports [two $10 \mathrm{~mm}$, two $5 \mathrm{~mm}$ ]. Pneumoperitoneum was created using $\mathrm{CO}_{2}$ gas creating a pressure of $12 \mathrm{mmHg}$. Cystic duct was clipped and cut in standard manner. Cystic artery was not clipped but dealt with energy sources. A retrieval bag was used to bring the GB out.

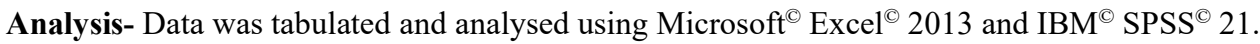

\section{Observations}

The number of cholecystectomies are gradually increasing and over last 2-3 years and have risen from around 250 to more than 400 this year in our institute. Based on convenient sampling method, 125 consecutive patients were selected for their inclusion in to the study. To reduce the inclusion bias, the sample group [125 patients] was matched for age and sex to study population group [total number of patients who underwent LC]. The female to male ratio was 2.94 and 2.90 [p $>0.05$ ] in the study population and sample group respectively. Mean age [in years] of female patients was 39.1 and 38.96 [p $>0.05$ ] while that of male patients was 43.3 and 41.91 [p $>0.05$ ] for study population and sample group respectively. Mean leukocyte count of the patients in sample group was 7802.8 /cumm and $16 \%$ of them had leucocytosis. Average total and conjugated bilirubin was 0.88 and $0.46 \mathrm{mg} / \mathrm{dl}$, respectively. Mean AST was $60.3 \mathrm{U} / 1$ and ALT was 9oo54.9 U/1. Average alkaline phosphatase level was $132.2 \mathrm{U} / 1$ and the value of GGT was $54.3 \mathrm{U} / 1$ [table 2]. On ultrasonography, average thickness of gallbladder wall was $3.6 \mathrm{~mm}$. GB was contracted in 6 [4.8\%] patients. Pericholecystic fluid was present in only 6 [4.8\%] patients. In 39 [31.2\%] patients, stone was impacted in the neck of gallbladder. Two [1.6\%] patients had solitary calculus and 3 [2.4\%] patients had polyp. The average size of the largest stone was $12.6 \mathrm{~mm}$ while the size of the stone impacted at infundibulum was $3.6 \mathrm{~mm}$. Liver echotexture was increased in 27 [21.6\%] patients and coarsened in 98 [78.4\%] patients [table/figure 2]. 
Original Research Article

Table 2: Preoperative variables: biochemistry and imaging.

\begin{tabular}{|c|c|c|c|c|}
\hline \multicolumn{2}{|c|}{ Variable/ Parameter } & Overall & Female & Male \\
\hline \multicolumn{2}{|c|}{ Total Leukocyte Count [per cumm, mean]* } & 7802 & 7894 & 7537 \\
\hline \multirow{6}{*}{ 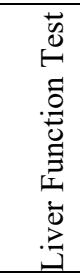 } & Total Bilirubin [mg/dl, mean] & 0.88 & 0.89 & 0.86 \\
\hline & Conjugated Bilirubin [mg/dl, mean] & 0.46 & 0.49 & 0.36 \\
\hline & AST [U/1, mean] & 60.3 & 58.2 & 66.5 \\
\hline & ALT [U/1, mean] & 54.9 & 52.03 & 63.3 \\
\hline & ALP [U/1, mean] & 132.2 & 127.6 & 145.7 \\
\hline & GGT [U/1, mean] & 54.3 & 52.4 & 59.8 \\
\hline \multirow{9}{*}{ 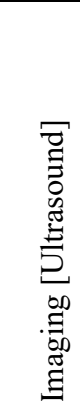 } & GB wall [mm, mean] & 3.6 & 3.7 & 3.4 \\
\hline & Contracted GB [n] & $6[4.8 \%]$ & 5 & 1 \\
\hline & Pericholecystic fluid [n] & $6[4.8 \%]$ & 5 & 1 \\
\hline & Solitary calculus $[\mathrm{n}]$ & 2 & 1 & 1 \\
\hline & Largest stone [mm, mean] & 12.6 & 12.3 & 13.5 \\
\hline & Impacted stone in neck or infundibulum [n] & $39[31.2 \%]$ & 25 & 14 \\
\hline & Size of impacted stone [mm, mean] & 3.6 & 3.02 & 5.3 \\
\hline & GB polyp [n] & 3 & 1 & 2 \\
\hline & Altered liver echotexture [n] & $27[21.6]$ & 24 & 3 \\
\hline
\end{tabular}

Table/Figure- 3: Parameter Response and Difficulty Response Score.

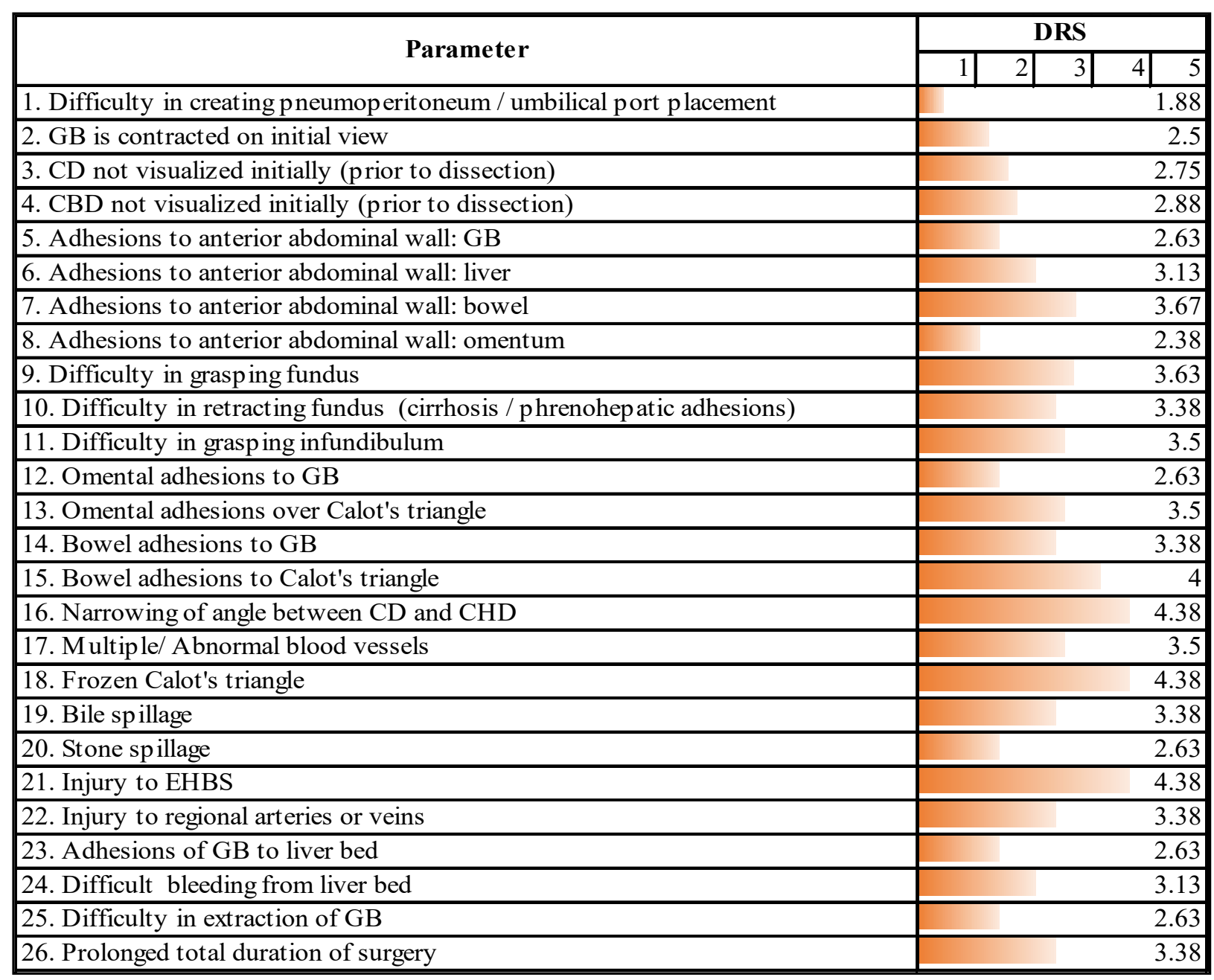




\section{Original Research Article}

An average of 144.7 litres of gas was used per case during the study. Harmonic ${ }^{\mathscr{O}}$ scalpel [84.8\%] and bipolar Maryland [53.6\%] were the energy source used during the study. The ease and the difficulty of surgery was graded on a scale of 1 to 5 by the practising laparoscopic surgeons across the country who responded to the questionnaire sent to them using Google ${ }^{\odot}$ Forms $^{\circ}$. A weighted difficulty score was calculated after the responses obtained from them [table/figure 3].

During surgery, we found the gallbladder contracted in 7 [5.6\%] patients. Cystic duct and CBD were not seen initially in 7 [5.6\%] and 5 [4\%] patients respectively. Omental adhesions to GB and Calot's were most common followed by other adhesions [table/figure4]. The angle between cystic duct and common hepatic duct was narrow in 4 [3.2\%] patients and Calot's tringle was frozen in 13 [10.4\%] patients. Multiple or aberrant vessels were present in cystohepatic triangle in 4 [3.2\%] patients. Peritoneal contamination was high as stone and bile spillage was present in 56 [44.8\%] and 15 [12\%] patients respectively. Main cystic artery was safely clipped in all cases but minor bleeding was present due to minor vessels in 55 [44\%] cases. There was one patient who suffered CBD injury which was recognized on table and dealt with. We encountered frozen cystic plate in 8 [6.4\%] patients leading to difficult removal. GB bed bleeding was there in 21 [16.8\%] patients. Conversion rate was $6.4 \%$ [ 8 patients]. Mean duration of surgery was 100.56 minutes.

Table 4: Intraoperative findings - adhesions.

\begin{tabular}{|l|c|c|c|}
\hline Intraoperative adhesions & \multicolumn{1}{l|}{ Overall } & Female & Male \\
\hline Omental adhesions to & $92[73.6 \%]$ & 66 & 26 \\
\hline 1. Gallbladder & $22[17.6 \%]$ & 13 & 9 \\
\hline 2. Calot's triangle & $13[10.4 \%]$ & 12 & 1 \\
\hline 3. Anterior abdominal wall/ falciform ligament & $9[7.2 \%]$ & 5 & 4 \\
\hline Other adhesions between & $17[13.6 \%]$ & 13 & 4 \\
\hline 1. GB and anterior abdominal wall & $1[0.8 \%]$ & 1 & 0 \\
\hline 2. GB and bowel & $28[22.4 \%]$ & 20 & 8 \\
\hline 3. Bowel and Calot's triangle & $1[0.8 \%]$ & 0 & 1 \\
\hline 4. Liver and anterior abdominal wall or diaphragm &
\end{tabular}

Mean WDS was found to increase with rising total leukocyte count (Pearson's correlation coefficient $=0.348$ ) and this positive correlation was statistically significant. $\left(\mathrm{p}=6.825 \times 10^{-5}\right)$. Mean WDS increased with rising total bilirubin (Pearson's correlation coefficient $=0.443, \mathrm{p}=2.163 \times 10^{-7}$ ) but was not found to be significantly changed with conjugated bilirubin level (Pearson's correlation coefficient $=0.108, \mathrm{p}=0.231$ ). The liver enzymes AST [Pearson's correlation coefficient $=0.572$, $\mathrm{p}=2.973 \times 10^{-12}$ ] and ALT [Pearson's correlation coefficient $=0.658, \mathrm{p}=6.230 \times 10^{-17}$ ] had a significant positive correlation with the WDS. Similarly, other liver enzymes including ALP [Pearson's correlation coefficient $=0.508, \mathrm{p}=1.382 \times 10^{-9}$ ] and GGT [Pearson's correlation coefficient $=0.586, \mathrm{p}=6.303 \times 10^{-13}$ ] too had a positive correlation that was statistically significant [table/figure 5, 6].

Table/Figure-5: Correlation coefficients of preoperative investigations.

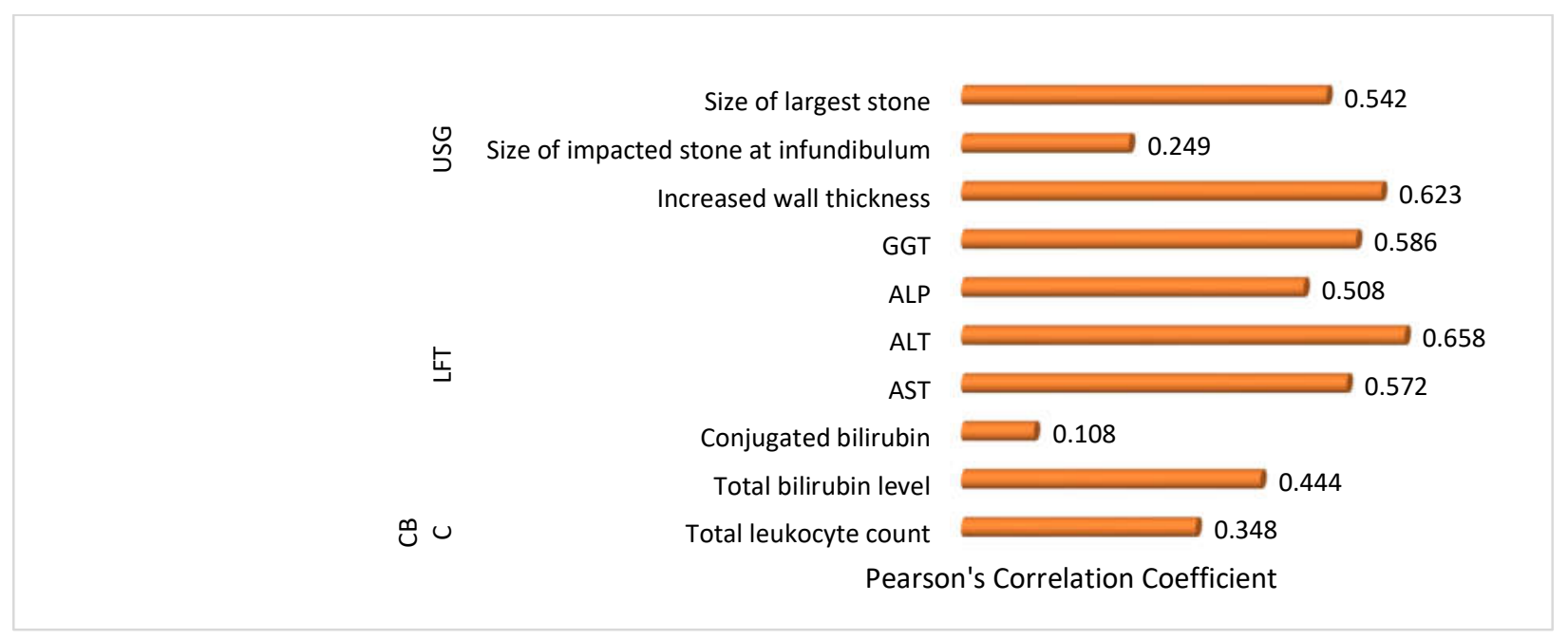




\section{Original Research Article}

Mean WDS increased significantly with wall thickness of gall bladder on ultrasonography (Pearson's correlation coefficient $=0.623, p=7.945 \times 10^{-15}$ ). Mean WDS was not found to be significantly changed with presence or absence of pericholecystic fluid on ultrasonography. It was 19.7 in patients with and 13.8 in patients without pericholecystic fluid $(\mathrm{p}=0.224)$. Mean WDS increased in patients with impacted stone on ultrasonography [21.8 in patients with and 10.6 in patients without impacted stone] and the difference was significant $\left(\mathrm{p}=1.49 \times 10^{-7}\right)$. Mean WDS was also found to increase significantly with the size of impacted stone at infundibulum $[\mathrm{r}=0.250, \mathrm{p}=0.005]$ as well as with the size of largest stone in GB $\left(r=0.542, p=6.162 \times 10^{-11}\right)$. Altered liver echotexture too was found to significantly affect WDS with a mean value of 21.01 compared to those with normal liver echotexture with a mean WDS of 12.2 [ $\mathrm{p}=0.00033$ ]. A contracted GB posed more difficulty during surgery compared to normally distended GB $\left[\mathrm{WDS}=39.7\right.$ and 12.6 , respectively, $\mathrm{p}=5.94 \times 10^{-11}$ ). The number of calculi hadn't been found to have any relation to WDS [14.39 in patients with multiple calculi and 8.98 in patients with solitary calculus, $\mathrm{p}=0.515]$ [table/figure 5,6$]$.

Table 6: Significance of correlation of various clinical parameters in predicting difficult laparoscopic cholecystectomy [in descending order].

\begin{tabular}{|c|c|c|c|c|}
\hline P value & Parameter & $\begin{array}{c}\text { Statistical } \\
\text { association }\end{array}$ & $\begin{array}{c}\text { Pearson correlation } \\
\text { coefficient (r) }\end{array}$ & Data \\
\hline $6.230 \times 10^{-17}$ & ALT & Significant & 0.658 & Continuous \\
\hline $7.945 \times 10^{-15}$ & Increased wall thickness & Significant & 0.623 & Continuous \\
\hline $6.304 \times 10^{-13}$ & GGT & Significant & 0.586 & Continuous \\
\hline $2.973 \times 10^{-12}$ & AST & Significant & 0.572 & Continuous \\
\hline $5.94 \times 10^{-11}$ & Contracted gall bladder & Significant & & Nominal \\
\hline $6.162 \times 10^{-11}$ & Size of largest stone & Significant & 0.542 & Continuous \\
\hline $1.382 \times 10^{-9}$ & ALP & Significant & 0.508 & Continuous \\
\hline $1.49 \times 10^{-7}$ & Stone impacted at infundibulum & Significant & & Continuous \\
\hline $2.163 \times 10^{-7}$ & Total bilirubin level & Significant & 0.444 & Continuous \\
\hline $6.825 \times 10^{-5}$ & Total leukocyte count & Significant & 0.348 & Nominal \\
\hline 0.00033 & Liver echotexture & Significant & & Continuous \\
\hline 0.005 & Size of impacted stone at infundibulum & Significant & 0.249 & Nominal \\
\hline 0.515 & Solitary or multiple calculi & Insignificant & & Continuous \\
\hline 0.231 & Conjugated bilirubin & Insignificant & 0.108 & Nominal \\
\hline 0.224 & Presence of pericholecystic fluid & Insignificant & & \\
\hline
\end{tabular}

\section{Discussion}

If we look at the disease burden in the state and then compare it to available literature, we find hardly few articles around. This isafter the hospital statistics show cholecystectomies constitute almost $70 \%$ of all surgical procedures $[3,4]$. Patient profile here is typical of any hilly area in the country where people get adjusted to a higher threshold of tolerance to pain either due to socio-cultural practices or mainly due to poor outreach of health services. And therefore a "difficult gallbladder" is not uncommon to find during LC.

We found leucocytosis in acute phase of the disease is associated with difficult surgery. Leucocytosis may be a reflection of extent of involvement of pericholecystic tissue which can cause difficulty during surgery even in the elective setting. Similar findings have been reported by various other authors where they have found the incidence of leucocytosis almost similar to that in our study [16-18\%], Kumar found it to be less than $10 \%$ while in Yetkin's study it was $56.17 \%$, however, all of them found it to be risk factor for difficult surgery[5-8]. Elevated bilirubin in cholecystitis is not a common finding when we see the literature as is the case in present study [4\%] but various studies including us have reported that raised bilirubin levels are associated with difficulty during surgery and resultant more chances of conversion $[7,9,10]$. We found an independent positive correlation of increase in liver enzymes viz aspartate aminotransferase, alanine aminotransferase, alkaline phosphatase and $\gamma$-glutamyl transpeptidase with difficulty in LC. Vivek, Alponat and Kama mentioned in their research that chances of adhesiolysis are increased and Calot's triangle dissection becomes difficult if there is a history of liver dysfunction $[9,11,12]$. It was concluded from our study that difficulty arises during the course of surgery if wall thickness is increased in pre-operative 


\section{Original Research Article}

ultrasonography. GB wall thickness has been identified as a risk factor for conversion. The critical thickness of GB wall associated with conversion varies from study to study. It was $3 \mathrm{~mm}$ to $6 \mathrm{~mm}$ in different studies. In a study conducted by S. Kumar it was $4 \mathrm{~mm}$. The same has been confirmed by other researchers like Lal, Nachnani and Baki who considered GB wall thickness to be the most important sonographic risk factor of conversion to open cholecystectomy [5,13-15]. We didn't find significant correlation between the presence of Pericholecystic fluid on pre-operative ultrasonography and difficult course of surgery. Surprisingly we had the least number of patients who had been shown to have pericholecystic fluid in abdominal sonography [4.8\%]. The proportion is varied ranging from $8 \%$ to $37 \%$ in various other articles. In contrast to our study, the other studies had shown the presence of pericholecystic fluid as a risk factor for conversion to open procedure $[6,7,14,16]$. Level of operative difficulty was found to increase with the finding of contracted GB on ultrasonography in our study. The finding was not universally supported in literature as Kumar, Nachnani and Vivek found evidence in favour of it while Baki suggested that course of surgery was not related to the shape of the gallbladder $[5,9,14,15]$.

Altered liver echotexture was a predictor of difficult LC in our study. Though literature is silent over this particular finding of 'altered liver echotexture', there are series which have reported that patients with cirrhosis took longer time and had more conversions as well as raised incidences of postoperative complications. Altered liver echotexture may be an indication of liver pathology especially cirrhosis or pre-cirrhotic changes that can pose difficulty during surgery [17-19]. Presence of stone itself causes difficulty at times. We found that surgery becomes difficult in cases having the stone impacted in neck or infundibulum as there will be difficulty in grasping the gall bladder due to over distension and the level of difficulty increases with size of impacted stone at infundibulum. Operative time was found to increase with the presence of a large stone even in absence of impaction at neck. Jansen found a stone size of $>20 \mathrm{~mm}$ if impacted at Hartmann's pouch made the dissection difficult [20]. Lal and Kumar too find a similar association of impacted stone with increasing difficulty in surgery $[5,13]$. Kumar and other authors also found that operative difficulty had an association with the increased size of stone but few other like Kama and Fried could not establish this association [5, 12, 21]. Most controversial of all is the number of stones. In our study, number of stones whether single or multiple couldn't find an association with difficult surgery. Nachnani too in his series didn't find any association between number of stones and risk of conversion however Vivek found multiple stones were associated with difficult Calot's triangle dissection as well as gallbladder extraction [9, 14]. On the other hand Kumar noticed that a single stone had more chances of conversion. Baki too supported him with his finding of association of single large stone with longer operative time [15].

\section{Conclusion}

As the field of surgery is evolving, the minimum invasive surgery is becoming the undisputed leader at least in the elective setup. And laparoscopic cholecystectomy is the gate way to it. With time, LC has become safer, the procedure is standardized, steps are defined and therefore is serving as a research tool for advanced minimum invasive surgery like reduced port surgeries, single incision laparoscopic surgeries, natural orifice transluminal endoscopic surgery and much more. The importance of preoperative prediction of a possible difficulty lies with the fact that the LC is now regarded as a very basic procedure among the people, for three reasons: for its volume, increasing awareness and availability of information. LC in present scenario is slowly converting towards day care surgery and with it the mindset of people considering it as a minor procedure and not understanding the complications associated with it.In the era of increasing litigation, the present study can help the professionals in explaining and informing the patient about possible complicationsthat can happen during difficult surgery and inform beforehand the cases who are likely to have a difficult surgery.

Contribution- KN, PB, VKS, BK and $\mathrm{NJ}$ were the operative surgeons. BKS was associated with the imaging work up. Data collection and tabulation was done by PB, BK and NJ. Statistical analysis was mainly handled by $\mathrm{KN}$ and VKS. All the authors were actively involved in the manuscript writing.

\section{Conflict of interest: None declared. Funding: Nil, Permission from IRB: Yes}

\section{References}

1. Sain AH. Laparoscopic cholecystectomy is the current "gold standard" for the treatment of gallstone disease. Ann Surg. 1996; 224(5): 689-690.

2. Jackson PG, Evans SRT. Biliary system. In: Townsend CM, Beauchamp RD, Evers BM, Mattox KL, editors. Sabiston textbook of Surgery, the biological basis of modern surgical practice. $20^{\text {th }}$ edition. Philadelphia: Elsevier. 2017. 1482.

3. Kotwal MR, Rinchen CZ. Gallstone disease in the Himalayas (Sikkim and north Bengal): causation and 


\section{Original Research Article}

stone analysis. Indian J Gastroenterol. 1998 Jul-Sep;17 (3): 87-9.

4. Kharga B, Sharma BK, Singh VK, Nishant K, Bhutia P, Tamang $\mathrm{R}$ et al. Obesity not necessary, risk of symptomatic cholelithiasis increases as a function of BMI. JCDR. 2016;10(10):PC28-32. DOI: 10.7860/JCDR/ 2016/ 22098.8736.

5. KumarS, Tiwary S, Agrawal N, Prasanna G, Khanna R, Khanna A: Predictive Factors for Difficult Surgery in Laparoscopic C holecystectomy for C hronic C holecystitis. The Internet Journal of Surgery. 2008;16(2). DOI: $10.5580 / 154 \mathrm{e}$.

6. Yetkin G, Uludag M, Citgez B, Akgun I, Karakoc S.Predictivefactors for conversion of laparoscopic cholecystectomy in patients with acute cholecystitis. Bratisl Lek Listy. 2009;110(11):688-91.

7. Lipman JM, Claridge JA, Haridas M, Martin MD, Yao DC, Grimes KL, Malangoni MA. Preoperative findings predict conversion from laparoscopic to open cholecystectomy. Surgery. 2007 Oct;142(4):556-63; discussion 563-5.

8. Rosen M, Brody F, Ponsky J. Predictive factors for conversion of laparoscopic cholecystectomy. Am J Surg. 2002 Sep;184(3):254-8.

9. Vivek MAKM, Augustine AJ, Rao R: A comprehensive predictive scoring method for difficult laparoscopic cholecystectomy. Journal of Minimal Access Surgery. 2014; 10:2.DOI: 10.4103/0972-9941.129947.

10. Polychronidis A, Botaitis S, Tsaroucha A, et al Laparoscopic Cholecystectomy in Elderly Patients. J Gastrointestin Liver Dis. 2008;17(3):309-313.

11. Alponat A, Kum CK, Koh BC, Rajnakova A, Goh PM. Predictive factors for conversion of laparoscopic cholecystectomy.World JSurg.1997Jul-Aug;21(6):629-33.

12. Kama NA, Kologlu M, Doganay M, Reis E, Atli M, Dolapci M. A risk score for conversion from laparoscopic to open cholecystectomy. Am J Surg. 2001 Jun; 181 (6): $520-5$.
13. Lal P, Agarwal PN, Malik VK, Chakravarti AL. A difficultlaparoscopic cholecystectomy that requires conversion to openprocedure can be predicted by preoperative ultrasonography. JSLS. 2002 Jan-Mar;6(1): $59-63$.

14. Nachnani J, Supe A. Pre-operative prediction of difficult laparoscopic cholecystectomy using clinical and ultra-sonographic parameters. Indian J Gastroenterol. 2005 Jan-Feb;24(1):16-8

15. Nachnani J, Supe A. Pre-operative prediction of difficult laparoscopic cholecystectomy using clinical and ultrasonographic parameters. Indian J Gastroenterol. 2005 Jan-Feb;24(1):16-8.

16. Gholipour C, Fakhree MBA, Shalchi RA, Abbasi M. Prediction of conversion of laparoscopic cholecystectomy to open surgery with artificial neural networks. BMC Surgery. 2009; 9:13, DOI:10.1186/1471-2482-9-13.

17. Morino M, Cavuoti G, Miglietta C, Giraudo G, Simone P. Laparoscopic cholecystectomy in cirrhosis: contraindication or privilegedindication?Surg Laparosc Endosc Percutan Tech. 2000 Dec;10(6):360-3.

18. Shaikh AR, Muneer A. Laparoscopic cholecystectomy in cirrhotic patients. JSLS. 2009 Oct-Dec;13(4):592-6. doi: 10.4293/108680809X12589999537959.

19. Laurence JM, Tran PD, Richardson AJ, Pleass HC, Lam VW. Laparoscopic or open cholecystectomy in cirrhosis: a systematic review of outcomes and metaanalysis of randomized trials. HPB (Oxford). 2012 Mar; 14 (3):153-61. doi: 10.1111/j.1477-2574.2011. 00425.x. Epub 2012 Jan 18.

20. Jansen S, Jorgensen J, Caplehorn J, Hunt D. Preoperative ultrasound to predict conversion in laparoscopic cholecystectomy. Surg Laparosc Endosc. 1997 Apr; 7(2):121-3.

21. Fried GM, Barkun JS, Sigman HH, Joseph L, Clas D, Garzon J, Hinchey EJ, Meakins JL. Factors determining conversion to laparotomy in patient sunder going laparoscopic cholecystectomy. Am J Surg. 1994 Jan;167 (1): 35-9; discussion 39-41.

\section{How to cite this article?}

Kumar N, Bhutia P, Singh V.K, Kharga B, Sharma B.K, Jain N. Prediction of difficult laparoscopic cholecystectomy while working up the patient for surgery. Surgical Update: Int J surg Orthopedics. 2017;3(4): 107-113.doi:10.17511/ijoso.2017. i04.03. 